(Aus dem zoologischen Institut der Universitit zu Freiburg i. B.)

\title{
Zur Kenntniss der Spermatogenese von Gryllotalpa vulgaris Latr.
}

Mit besonderer Berücksichtigung der Frage der Reductionstheilung. Von

\section{Dr. O. vom Rath.}

Hierzu Tafel V.

Seit längerer Zoit bin ich mit vergleichenden Untersuchungen uber die Samenhildung bei Wunmem, Arthropoden, Mollusken und Vertebraten bechäftigt. Ausser den allgemeinen Fragen der Zellennorphologie unt Zellenbiologie, für welche bekanntlich die Sexualzellen schon wegen ihrer Grösse besonders giinstige Cntersuchungsobjecte abgeben, kamen in erster Linie folgende Gesichtspunkte in Betracht: I. An weleher Stelle und in welcher Weise findet in der Samenbildung die von We ismann theoretisch geforderte Reduction des Chromatins (Reductionstheilung) statt? II. Wie vollzicht sich die Umbilkung der unreifen Samenzellen (Spermatiden) zu reifen Samenfüden (Spermatozocn)? III. Welche Bedeutung hat die amitotische Kentheilung in Hoden? Da eine Beantwortming dieser drei Tagesfragen nicht gut bei" ein und demselben Objecte $z u$ erwarten war, lag es nahe die Spermatogenese einer grösseren Zahl von Vertretern verschiedener Thiergruppen gleichzeitig in Angriff zu nehmen und zu verschiedenen Jahreszeiten $\%$ studiren.

Für die Beantwortung der ersten Frage ist Gryllotalpa ein hesonders geeignetes Object, da die Zahl und Grösse der Chromosomen ein genaues Zählen zulässt, und die wichtigen Vorgänge vor deu beiden letaten Theilungen viel klarer und verständlicher sind als bei allen anderen von mir untersuchten Thieren. Nebenhei war es von Wichtigkeit festzustellen, ob die von $\mathrm{Henk}$ in $\mathrm{g}$ (Nr. 5) hei Pyrrhocoris apterus beschriebenen Resultate auch bei allen anderen Insecten Geltung haben, oder ob vielleicht in der Samenbildung des einen oder des anderen Insectes Verhältnisse angetroffen werden, welche sich den von 0 . Hertwig (Nr. T) bei 
Ascaris megalocephala eruirten Befunden anschliessen. Ich will hier aber nicht zu betonen unterlassen, dass ich bei meinen Untersuchungen vollkommen unparteiisch und objectiv vorging, um zunächst nur eine Reihe von Thatsachen festzustellen, auf die hin erst später theoretische Betrachtungen angeknïpft werden sollen.

Meine Studien über die Samenbildung von Gryllotalpa hahe ich im Frühjahr vorigen Jahres begonnen and bis in den Herbst hinein weitergeführt. Eine vorläufige Mittheilung (Nr. 12 b) der wesentlichsten Resultate ist bereits im September vorigen Jahres erschienen. Mein Material erbeutete ich reichlich in den Gärten des zoologischen Instituts, besonders unter alten Brettern, welche absichtlich auf verwesendem Laube niedergelegt worden waren.

Die Begattung und Eiablage von Gryllotalpa erfolgte in vorigen Jahre in rler Ungebung Freiburgs i. B. in der zweiten Hälfte des Juli his in die Mitte des August hinein. Die Männchen starben bald nach der Copulation; ich habe wenigstens nach dem 12. August kein Männchen mehr fangen können, während ich Weibchen, die ihre Eier abgelegt hatten, his in den Octoher hinein ziemlich zahlreich antraf. Letztere sollen einer Art von Brutpflege vorstehen und erst bei Beginn der kälteren Jahreszeit absterben.

Bei den frisch gefangenen Thieren wurden die Hoden heranspräparirt, was sehr leicht und schnell von Statten geht, und sofort conservirt. Die Hoden sind paarig und liegen reehts und links neben und über dem Darm; jeder der beiden Lappen besteht aus einer grossen Zahl von Follikeln, die etwa die Gestalt einer Rübe oder Birne haben und jeweils von einer derben doppelt contourirten Membran mit eingelagerten platten Kernen umhüllt sind. Der verjüngte Abschnitt eines jeden Follikels setzt sich in einen feinen Ausführungsgang fort, der dem Stiele der Birne zu vergleichen ist. Eine grössere Zahl solcher Ausführuingsgänge vereinigt sich zu einem gemeinsamen Sammelgang. Die am weitesten in der Entwicklung vorangeschrittenen Samenelemente liegen jedesmal in der Nähe des Ausführungsganges, während die jiungsten Zellen dementsprechend an dem blinden verbreiterten Theile der Follikel angetroffen werden. Bei dieser Anordnung findet man in jedem Follikel stets mehrere Entwicklungsphasen der Samenzellen nebeneinander, 
so dass über die Aufeinanderfolge der Stadien kein Zweifel obwalten kann. Nur bei den Hoden ganz junger Männchen, bei welchen die Theilumgen der Ursamenzellen zur Anschanung kommen, kann ans der Lage allein auf die Reihenfolge der Stadien nicht mit Sicherheit geschlossen werden, da verschiedene Zellgruppen in verschiedlenen Theilungsplasen nebeneinander liegren.

Bevor ich nun zu einer Beschreibung meiner Befunde übergehe, will ich noch einige Worte ither die Conscrvirungs- und Färbungsmethode voransschicken und die später zu verwendenden Termini feststellen. Nach dem empirischen Theil soll eine Besprechung der Literatmr und ein Vergleich meiner eigenen Resultate mit denen der früheren Autoren folgen.

\section{Conservirungs- und Färbungsmethodle.}

Von Conservirungstlüssigkeiten leisteten mir besonders gute Dienste die F l e m m in g'sche Chromessigosmimusäure, die H ermann'sche Flüssigkeit (mit Holzessigreduction), sowic ein von mir zusammengestelltes Gemisch von Pikrinessigrosmiumsäure (Nr. 12a). Weniger grute Bilder erhiclt ieh durch die viclfach (und zumal für die Ovogenese) beliobte Behandlung mit erwärmten Sublimatalcohol. Bei letzterer Wethorle kommen meist slie Centrosomen weniger gut zur Anschaumg und ist auch die Spaltung des Chronatinfadens im Knäuelstarlium weniger sicher zu erkennen als bei den anderen angeführten Methoden; dagegen erwies sich heisser Sublimatalcohol zur Conservirung ganzer, kleinerer Thiere, z. B. von Copepoden als sehr geeignet, da die so behandelten Thiere sofort absterben und dam die $\pi$ untersuchenden Organe in einer anderen Conservirungsflikssigkeit wciter gehärtet werden kömnen. Vielfach wurde anch der dem lebenden Thiere entnommene Hoden auf dem Ohjectträger zer"zupft und sofort untersucht; sehr schöne Bilder des frischen Hodens erhielt ich bei einer nur wenige Secunden währenden Färbung kleiner Stückchen mit wässeriger Methylenblaulösung. Bei den conservirten Hoden kam zumeist die Schnittmethode nach Paraffineinbettung in Anwendung; nebenbei wurden aber auch von gefürbten Hoden Zupfpräparate in Cedernholzöl hergestellt, die von besonderer Wichtigkeit sind, zumal wenn es sich $\%$. B. darmm handelt festzustellen, wamn im Knäuelstadium der bereits längsgespaltene Chromatinfaden durch Qnertheilnng in mehrere Segmente zergliedert wird. Die stets in 
Zur Keuntniss der Spermatogenese von Gryllotalpa vulgaris Latr. 105

absolutem Alcohol nachgehärteten Hodenstïcke wurden mit den ïhlichen Tinktionsmitteln in toto durchgefärbt mul einige Serien auf dem Objectträger mit Hämatoxylin, Boraxcarmin oder Anilinfarben naclgefärbt. Die besten Resultate erhiclt ich bei allen untersuchten Objecten durch cin 24stündiges Färben mit Alauncochenille im Paraffinofen bei $55^{\circ}$ Celsius. In letzter Zcit kam auch die Färbung mit Safranin-Gentiana-Orange nach entsprechender Vorbehandlung genau nach den Fle m m in g'schen Angaben in Anwendung. Dass stets mehrere Conservirungs- und Färbungsmethoden nebeneinander versicht wurden, braucht kanm erwähnt zu werden.

\section{Terminologie.}

Bezeichnung der verschiedenen Entwicklungsstadicn der Samenzollen. Da die von La Valette st. George (Nr. 14) eingeführten Ausdrücke Spermatogonien, Spermatocyten, Spernatiden, Spermatosonen zwar von den meisten Autoren angenommen wurden, aber keineswegs inmor in denselben Sime Verwendung gefunden haben, will ich zur Vermeidung von Missverständnissen die von mir yu gebranchenden Bezcichnungen zuvor feststellen. Ich unterscheide in der Samenbildlung von Gryllotalpa 4 Perioden. Erstens die Keimzellen-oder Vermehrungsperiode; zweitens die Wachsthums-oder Ruheperiode; drittens die Reifungsperiode (das ist die Periode der zwei letzten Theilungen) und viertens die U mwand l ungsperio de. Dic Zellen der ersten Periode nenne ich Ursanenzellen=Spermatogonien; die Zellen der zweiten Periode bezcichne ich mit Hertwig (Nr. 7, S. 8) als Samenmutterzellen. (Diese entsprechen etwa rlen Spermatocyten La Valette's). Die sich in der dritten Periode zweimal hintereinander theilenden Zellen sind Samentochterzellen. Es entstehen so aus jeder Samenmutterzelle 4 Samenenkelzellen (Spermatiden La Valette's), die sich in der vierten Periode obne weitere Theilung direct in Samenfäden (Spermatosomen oder Spermatozoen) umrandeln.

Ueber einen Ersatz der Bezeichnungen Chromosom und Ahnenplasmen durch Idant und Ide. Bekanntlich werden die Chromatinkörper, welche sich bei der Caryomitose in der Aequatorialplatte der Spindel aufstellen, als Kernschleifen, Kernstäbchen, Chromosomen, Chromatophoren etc. benannt. Eine einheitliche Bezeichung entspricht zwar eineul dringenden Be- 
dürfnisse, ist aber schwer zu geben. Weismann hat in seiner Amphimixis (Nr. 15) für diese wechselnden und willkürlichen Bezeichnungen den Ausdruck Idant und für die den Idanten zusammensetzenden Almenplasmen die Bezeichnung Ide eingeführt. „Die Ausdrücke Id und Idant sollen an $\mathrm{N} a ̈ g$ geli's Idlioplasma erinnern, deren Theile sie sind." Ich werde zur Verhütung jeglichen Missverständnisses bei der Darstellung meiner eigenen Befunde einstweilen den Ausdruck Chromosom beibehalten.

Was verstelit man unter Reductionstheilung? Die meisten Autoren, welche den Gerlanken der Reductionstheilung angenommen haben, denken bei diesem Vorgang einfach an eine Massenreduction des Chromatins, die mit einer Herabsetzung der für die betreffende Thierart typischen Zahl der Chronosomen (Idanten) auf die Hälfte verbunden ist. Eine solche Auffassung entspricht aber nicht genau einer Reductionstheilung im Sinne Weismann's. Im Gegensatz zur dequationstheilung, bei welcher sämmtliche Mhnenplasmen (Ifle) gleichmässig aut die Tochterkerne vertheilt werden, wirl bei der Reduetionstheilung nach Weismann die Zahl der Ahnenplasmen (Ide) halbirt und dem einen Tochterkerne werden diese, dem anderen jene thnenplasmen (Ide) zugefïhrt. „Unter Reductionstheilung verstehe ich, sagt $W$ eismann in seinem letztenWerke (Nr. 15), eine jede Kerntheiltung, durch welche die Zahl der Irle, welche im ruhenden Kern vorhanden war, für die Tochterkerne auf die Hälfte herabgesetzt wird; unter dequationstheilung eine solehe, durch welche jeden Tochterkern die volle Id Ziffer des ruhenden Kerns der Yutterzelle zugeführt wird. Im letzteren Fall wird zugleich jeder Tochterkern dieselben Ide erhalten, im ersteren würde dies nur in dem Falle eintreten müssen, wenn der Mutterkern lauter identische Ide enthielt.“

\section{A. Empirischer Theil.}

\section{Die Periode der Theilungen der Ursamenzellen (Sperma- togonien).}

Die ersten jungen Gryllotalpa-Männchen erbeutete ich anfangs Mai und ich fand in den Hoden derselben eine überaus rege Theilung der Ursamenzellen vor. Die Hoden waren za dieser Jahreszeit moch sehr klein mol es hatten die einzelnen Follikel bei weitem nicht die Hälfte ihrer späteren Grösse 
Zur Kemntniss der Spermatogenese von Gryllotalpa vulgaris Latr. 107

erreicht. In jedem Follikel sah ich mehrere Generationen von Ursamenzellen gleichzeitig in den versehiedenen Phasen der Caryomitose, die bei sänmtlichen Generationen in gleicher Weise zu verlanfen schien und keine Abweichung von dem gewohnten Schema der Mitose der Somazellen erkennen liess. In den Fig. 1-9 habe ich die versehiedenen Theilungsstadien der Reihe nach darzustellen verstcht; die Abbildungen selbst bedürfen kanm einer weiteren Erklärnng. Fig. 1 stellt eine Ursamenzelle im Ruhestadinm dar; der bläschenförmige Kern lässt eine deutliche Membran erkennen und das gesammte Chromatin ist in demselben in Form cines feinmaschigen Netzwerkes vertheilt; meist fallen zwei intensiv tingirte Nueleolen auf, dic bei den Vorbereitungen der Theilungen sehr lange persistiren und sich erst im letzten Knänelstadlium allmählich der Bcobachtnng entzichn. Der Begimm einer Theilung wird darlurch kenntlich, dass zuerst das feine Maschenwerk grober wird (Fig. 2.), und sich dann das Chromatin von der Kernmembran zuriickzicht und nach einer Seite hin in Form eines unregelmässig. gestalteten Klumpens zusammenballt Nig. 3. (Man vergleiche die :i hnlichen Vorgänge, welche $\mathrm{H}$ e r m a n $\mathrm{n}(\mathrm{Nr}$. 6) beim Salamander beschrieben hat.) Der Klumpen besteht aus fein gekörnelten Chromatinfäden und einzelne derselben treten aus dem Klumpen hervor und durchsetzen hier und dort den scheinbar leeren Kernraum.

Dis gesammte Chromatin ordnet sich jetst in Form eines einzelnen dünnen, vielfach verschlungenen Fadens an, der selbst aus Linin besteht und an welchem die kleinen Chromatinkügelchen perlschnurartig aneinander gereiht sind (Knäuelstadium). Dieser Farlen, welcher den gesammten Kern in vielen Windungen und Krïmmungen durchsetzt, wird allmählich dicker, indem die Chromatinkügelchen (Mikrochromatosomen) offenbar durch die Contractionen des Linins mehr und mehr mit einander verkleben, wolurch der Faden ein böckriges Aussehen gewinnt (Fig.4). Bei gut conservirten Präparaten kann man um diese Zeit bei Anwendung starker Vergrösserungen dentlich eine bereits vollzogene Längsspaltung des Fadens erkennen; die so entstandenen Schwesterfäden trennen sich aber nicht von einander, vielmehr sind dieselben an vielen Stellen noch miteinander verklebt (Fig. 4 a u. 4 b). Der Doppelfaden zerfällt nun seinerseits durch Quertheilungen in 12 gleich grosse Segmente, bei denen gleichfalls die Schwester fäden miteinander vereinigt bleiben. Für dieses Stadium sind 
Zupfpräparate von grosser Wichtigkeit, da nıan an diesen die Zahl 12 mit Sicherheit feststellen kann, während anf Schnitten manchmal durch Anschneiden der Segmente eine grössere Zahl zur Anschauung kommt. In Figur $4 a$ habe ich eine Abbildung eines Kernes mit quergetheiltem Faden nach einem Schnitt und in Figur $4 \mathrm{~b}$ nach einem Zupfpräparat gegeben. Die einzelnen Segmente verkürzen sich jetzt mehr und mehr und stellen sich schliesslich als 12 runde Chromosomen in der Aequatorialebene auf. Ich habe mich vergeblich beniiht an einem solchen Chromosom eine Andeutung davon zu erkennen, dass es eigentlich ans zwei Hälften besteht, die dann auf der Höhe des Aequators endgültig von einander getrennt werclen. Durch die schon im Knäuelstadium rurch Verdoppelung des Chromatinfadens vorbercitete uud jetzt zum Vollaug kommenile Längsspaltung werden num die 12 Chromosomen getheilt und nach jedem Pol der Spindel wieder 12 Chromosomen (aber von der halben Grösse) ange\%ogen. Bei Conservirung nit Pikrinessigosmiumsïure sind an der Spindel bei der Seitenansieht die Centrosomen und eine Strahlungr (Fig. ठ̌). Da die Spindelfiguren vom Pol aus gesehen und auch von der Scite alus betrachtet (Figr. 5 n. 6) sehr häufig sind, gelang es mir nicht selten, die Zahl 12 fiur die Chromosomen aller Generationen der Ursamenzellen als typisch festzustellen, von welchen hei der Seitenansicht der Spindel meist fünf bis sieben zu erkennen sind (vergl. Fig. 5). Werfen wir nun noch einen Blick auf die Fig. 4 a u. 4 h zuriick, so erkennen wir bereits früh im Knäuelstadium zwei anseinanderweichende winzige Centrosomen; ich muss hier aber bemerken, dass ich letztere nur bei Anwendung bestimmter Conservirungs- und Färbungsmethoden in ganz seltenen Fällen nach längerem Suchen mit den stärksten Vergrösserungen auffinden konnte, ich möchte daher über ihr erstes Auftreten nichts Sicheres behanpten; in ruhenden Zellen mit bläschenförmigen Kernen habe ich bei Gryllotalpa nie eine Spur eines Centrosomas oder einer Attractionssphäre erkennen können. Wenn nun anch, wie ich vorhin betonte, die Caryomitose sänıntlicher Generationen der Ursamenzellen in gleicher Weise zu verlaufen seheint, so fallen doch Bilder auf (Fig. 8c), bei welchen von den 12 Chromosomen stets zwei and wwei einander genähert sind, ohne aber durch eine cliromatische Brücke verbunden zu 
Zur Kenntniss der Spermatogenese ron Gryllotalpa vulgaris Latr. 109

sein. Wie diese paarweise Gruppirung zu Stande kommt, war mir nicht möglich zı eruiren.

\section{Die Periode der Ruhe und des Wachsthums der Samen- mutterzellen.}

Nachdem die Ursamenzellen sich während der ersten Periode beständig durch mitotische Theilungen vermehrt haben, wodurch die Zellen selbst an Grösse etwas eingebuisst, die Follikel aber und Hollenlappen wesentlich zugenommen haben, tritt plötzlich eine allgemeine Periode der Ruhe ein, während weleher die Zellen eine Zumahme des Zellplasma erfahren; ich bezeichne dieselben jetzt als Samenmutterzellen. Eine Dotterbildung, wie sie von Hertwig (Nr. 5) bei Ascaris meg. und vou Henking (Nr. 5) bei Pyrrhocoris apt. während dieser Periode beschrieben wurde, ist mir bei Gryllotalpa nicht \%ur Anschaumig gekommen. Die ruhenden Samennutterzellen zeigen in dieser Zeit eine regelnässige rosettenfömige Gruppirung, inden jeweils eine grössere Zahl solcher Zellen mit ilnen Spitzen mm ein gemeinschaftliches Centrum angeordnet ist (Fig. 9). Eine derartige Gruppirung ist bei der Spermatogenese der Insecten häufig anzutreffen; sehr typisch ist sie bei den Samenmutterzellen der Drohnen. Der Habitus der Samenmutterzellen von Gryllotalpa ist von dem der ruhenden Ursamenzellen nieht wesentlich versehieden. (Vergl. Fig. 1 und Fig. 9.) Der bläschenförmige Kern der Samemuntterzellen ist anffallend blass und das Chromatin ist in einem noch feineren Maschenwerk durch den Kern rertheilt als bei den Ursancnzellen. Das Zellplasma erscheint feinkörnig, lässt aber bei Anwendung starker Vergrösserungen ein vielfach verschlmngenes Gerïstwerk feiner Fasem deutlich erkemnen. Mit auffallender Regelmässigkeit färben sich die Zellspit\%en viel dunkler wie der nibrige Zelleib und man kann läufig in diesen dunklen Partien eine Andeutung einer strahligen Anordnung erkennen; doch gelang es mir bei keiner Methode dort ein Centrosoma zur Anschaumg zu bringen. Das Ruhestadium der Saniemuntterzellen beobachtete ich in der zweiten Hälfte Mai, es seheint aber nicht lange zn danern, da ich durchgängig bereits anfangs Juni die Vorbereitungen der beiden letzten Theilungen antraf. Eine lingerc Ruheperiode dürfte bei den Samennutterzellen von Gryllotalpa überflüssig sein, da die Vermehrung des Zellplasma cine relativ geringe ist. 


\section{Die Periode der Reifung und der beiden letzten Thei- lungen.}

Die Vorbereitungen zu einer neuen Theilung werden dadurch kenntlich, dass plötzlich und fast gleichzeitig sämmtliche ruhenden Zellerne im gesammten Hoden in das Kuäuelstadim eintreten, während nur einige wenige Zellen an blinden Ende der Follikel im Ruhezustand verharren und welche ans Analogie als Regenerationszellen gedentet werden künmen. Die verschiedenen Prophasen der Theilung habe ich in den Fig. 10-15 dargestellt. Bereits in Stadium des feinen Knäuels Figr. 12 komte ich bei Pikrinessigosmiumsäure-Behandlung die Längsspaltung des Fadens erkenmen, es fehlte aber, wie ich auf Zupfipriparaten feststellen komnte, jede Andeutung der bald nachher erfolgenden Quertheilmugen, die im Stadium des groben Knäuels (Fig. 13) unverkennbar vollzogen sind. Ein Nucleolus ist bis in dies Stadium (Fig. 11) deutlich wahrnehmbar geblieben, während ein zweiter (Fig. 12) völlig unsichthar greworden ist. Soviel steht fest, dass die Nncleoli an dem Aufbau des chromatischen Fadens keinen directen Antheil nehmen. Wie bei den Theilungen der Ursamenzellen habe ich zwei winzige auseinanderweichende Centrosomen in seltenen Fällen bereits zur Zeit des feinen Kuäuels erkennen kömnen (Fig. 12). Anch bei den Theilungen der Tochter\%ellen möchte ich mich bei der Kleinheit des Objectes in Betreff des ersten Auftretens der Centrosomen sowie über die Bildung der Spindel jeglichen Urtheils enthalten mul nur erwälhnen, dass mir hin und wieder Bilder zur Anschaung kamen, die für eine Entstebung der Spindel imerhalb des Zellplasma zu sprechen schienen (Fig. 12) und eine nnverkembare Aehnlichkeit nit den diesbezüglichen Abbildungen Hermann's (N. 6) beim Salamander verriethen. Während aber firiher bei den Ursamenzellen durch Quertheilungen des Doppelfadens stets 12 Segmente hervorgingen (Fig. 13b), wird der Doppelfaden jetzt nur an 6 stellen der Quere nach durchgeschnirt; es kann folglich jeder der jetzt entstandenen Abschnitte zwei Segmenten lomolog gesetzt werden. Die Fadenalsschnittc rerküirzen sich und die Schrvesterfäden jedes Doppelsegmentes verlïthen an ihren freien Enden miteinamder (Fig. $13 d$ ) und so entstehen in Kerne 6 Chromatinringe, von denen jeder 4 Fadenstïcken oder 4 Chromosomen homolog ist. 
Diese 6 Ringe jedes Kernes liegen der Kernperipherie dicht an, so dass man nur durch Heben und Senken des Tubus die Sechszahl feststelleu kam, meist verdecken ein oberer wnd ein unterer Ring einander, so dass scheinbar nur 5 Ringe vorhanden sind. Dies Stadium (Fig. 13d), welches, wie wir nachher noch sehn werden von grosser Wichtigkeit ist, hat nur kurze Daner und kommt relativ selten zur Anschauung. Viel häufiger sieht man das nächstfolgende Stadium, in welchem sich aus jedem Ring 4 sternchenförmige, durch Linin mit einander verbundene Chromosomen herausdifferencirt haben (Fig. 14 u. 15). Wir seben so 6 Gruppen von je 4 Chromosomen oder 24 Einzelchromosomen. Es sind aber nun nicht nur je vier Chromosomen miteinander durch Linin verbunden, vielmehr sieht man auch feine Lininfäden vou gekürneltem Ausselın zwischen den Chromosomen versehiedener Gruppen verlaufen, so dass sümmtliche 24 Chromosomen in einem gewissen Zusammenhang stehen, und späterhin durch die Contractionen des Linins von der Kernperipherie in das Kernimnere zusammengezogen werden. Da nun die 4 Chromosomen jeder Gruppe keineswegs in einer Ebene liegen, so sind von einigen Gruppen oft nur zwei Chromosomen sichtbar, da die zwei anderen dureh sic verdeckt sind (Fig. 15). Sowohl für das Ringstadium als für dieses Gruppenstadium sind Zupfpräiparate von grossem Werthe. In Fig. 14 habe ich das Gruppenstadium etwas schematisirt nach einem Zupfpräparat und in Fig. 15 nach einem dickeren Schnitt in natülichen Lageverhältnissen abgebildet. Mit grösster Aufmerksamkeit habe ich die Verbindungsfäden zwischen je 4 Chromosomen stulirt, aber niemals eine Spur von chromatischer Substanz wahrgenommen, so dass die 4 Chromosomen jeder Gruppe als Einzelchromosomen und nicht die Gruppen selbst als Einheiten aufgefasst werden nüssen. Welche Bedeutung diese Frage hat, werden wir weiter nnten noch besprechen.

Die Zahl der Chromosomen ist folglich vor der ersten Theilung der Reifeperiode, aber nach der Ruheperiode (Periode II) von 12 auf 24 verdoppelt. Eine nähere Betrachtung einer solchen Gruppe (Fig. 1 4 u. 15) zeigt, dass die 4 Chromosomen in Form eines Vierecks (an den Ecken eines Quadrates) angeordnet sind; wie wir gleich noch näher ausfülhren werden, wird bei der ersten Theilung das Viereek durch eine dem einen Paar der Seitenwände parallele Theilungshinie getheilt und bei der zweiten Theilung 
ist die Theilungslinie senkrecht anf der ersten, geht also dem anderen Paar der Wände des ursprünglichen Vierecks parallel. Durch die beiden Theilungen entstehen so aus jeder der 6 Gruppen von 4 Chromosomen 4 Spermatozoen, deren jedes 6 Chromosomen und zwar je 1 Chromosom aus jeder Gruppe erhält.

Der Verlauf der beiden Theilungen ist folgender: Anstatt, dass sich die 24 Chromosomen sämmtlich in der Aequato rialebene der Spindel anfstellen, orthen sich die 24 Chromosomen (die jetzt völlig rund erselreinen) in. 2 parallelen Krainzen von je 12 Chromosomen an, sie stellen sich, "zweireilig" auf (Fig. 16 11. 19) und es wandern jetat nach jedem Pol 12 ungetheilte Chromosomen, somit erhält jede Tochterelle 12 Chromosomen, von denen auch wieler \%wei und zwei einander genähert sind, ohne aber dureh Chromatin miteinander verbunden zu sein (Fig. 17). Es stellen sich also bei der Spindelbildung jeweils die im Viereek angeordneten Chronosomen so in der Aequatorialebene auf, diass diese durch die Hälfte des Vierecks geht und dasselbe einer Seite parallel in wwei Hälften theilt. Hiermit ist die erste Reductionstheilung vollzogen und die typische Zahl 12 (die anf $2 \pm$ ver(oppelt war') wieder hergestellt. Bei der gleich anf die erste Theilung mit Ueberspringen des blaischenförmigen Ruhezustantes des Kernes erfolgenden \%weiten Theilung (Fig. 22-25), die wie gewöhnlich senkrecht auf die erste stattfindet, werden auch jeweils die 2 zu einander gehörenden Chromosomen (Paarlinge) getremnt und jede der vier Enkelzellen (Fig. 25), hat jetzt 8 Chromosomen womit die $z$ weite Reductionstheilung vollzogen ist.

Bei diesen Vorgängen ist vor allem dies festzustellen, dass beim Beginn der vorletzten Theilung die Zahl der Chromosomen das Doppelte der typischen Zahl beträgt, dass dann bei der vorletzten Theilung die verdoppelte Zahl auf die gewöhnliche Zahl reducirt and bei der letzten Theilung dic gew öhnliche Zahl auf die Hälfte herabgesetzt wird.

Betrachten wir nun einmal dic beiden letzten Theilungen (Reductionstheilungen) rom rein histologisehen Standpunkte ans, so fallen sofort mehrere crhebliche Abweichmngen von dem gewohnten Schena der Caryomituse auf', wie sie sonst im Thierreich nur noch bei der Bildung der Richtungskörper beschrieben sind. 
Zur Kenntniss der Spermatogenese von Gryllotalpa rulgaris Latr. 113

Erstens: Zwischen den beiden sofort anfeinander erfolgenden Theilungen gehn die beiden Tochter\%ellen nicht wie gewöhnlich ein Ruhestadium ein, womit zusammenlı̈̈ngt, dass die zweite Theilung ohne die gewohnten.Vorbereitungen (Knäuelbil/ung und Fadenspaltung stattfindet; zweitens ist zu beachten, dass bei beiden Theilungen auf der Höhe des Aequators keine Durcllschnürmg der einzehen Chromosomen stattfindet, viehnehr werden zweimal hintereinander die nur durch Linin miteinander verbundenen Chromosomen (Paarlinge) definitiv von einander getrennt. Bei der Beurtheilmng dieser eigenthümlichen Kerntheilungen wirl man zunächst daran denken, dass die Theilungen der Chromosomen, welche sonst in der Aequatorialebene stattfinden (aber stets durch die Längsspaltung des Chromatinsfadens im Knäuelstadium vorbereitet sind), bereits vorzeitig statigefunden haben; es kimn folglieh die eine der beiden Tremungen der Chromosomen anf diese vorzeitige Spaltung des Chromatinfadens zurrïckgefiilırt werlen, ob dies nun aber die erste oder die zweite Theilung ist, kann nach den Priparaten nicht mit Sicherheit entschicden werden, ich möchte eher an die zweite Theilmg denken.

Ich will hier aber nicht zu erwähnen unterlassen, lass bei manchen Thieren und zumal bei den Copepoden die Vorbereitungen zu den beiden letzten Theilnngen in der Ovogenese und Spermatogenese derselben Thiere wesentlich von einander verschieden sind. Besonders deutlich sah ich bei den marinen Copepoden Encheta und Calanus, lass die Spaltung des Chromatinfadens und Verdoppelung der Zahl der Chromosomen vor der ersten Theilung in der Orogenese weit früher schon-in der Periole II, in welcher die Vergriossertung und Dotterbildung der Eimntterzellen stattfindet deutlich wahrnehmbar sind, während dieselben Vorgänge in der Spermatogenese derselben Thiere erst in Periode III (Reifungsperiode) stattfinden, so dass in der Eibildung die Verdoppelung des Fadens noch weiter vorverlegt ist, als in der Samenbillung. Dieser frihlzeitige Verdoppelungsprocess in der Ovogenese hängt aber unzweifelhaft damit zusammen, dass die Periode des Wachsthums der Eimutterzellen wegen der erheblichen Grössenzunahme und Dotterbildung der tmreifen Eier wesentlich lïnger andanert als die entsprechende Wachsthumsperiode (Periode II) in der Spermatrogenese. Ich möchte dalier anch keineswegs den Verdoppelungsprocess in der Ei- und Samenbildung als eine rou den beiden 
letaten Theilungen unabhängigen Vorgang hinstcllen. Auch die Art und Weise der Vorbereitungsvorgänge sor clen beiden letzten Theilungen sind bei vielen Copepoden in ter Ei- uncl Samenbíldung desselben Thieres wesentlich von einander verschieden. In der Ovogenese konnte ich stets und besonders schön bei den marinen Formen Eucheta und Calanus eine typische Ring-Kranzbildung beobachten, ohne dass mir ähnliche Bilder in der Samenbildung derselben Thiere zur Anschaumy gekommen wären.

\section{Die Perjode der Umwandlung.}

Für die Beantwortung der Frage, in welcher Weise sich die umreifen Samenzellen (Spermatiden) in Samenfïlen (Sppermatosomen, Spermatozoen) umwandeln, und aus welehen Theilen der Samenzelle der Samenfulen, der seine Zellemnatur meist gänzlich eingebüsst hat, zusammengesetzt ist, gibt (rryllotalpa kein giinstiges und entscheidendes Object ab. In den Figuren 25-28 habe ich alles wiederugeben versucht, was ich bei Anwendung der stïrksten Verorïsserungen (bis zu 2000) mit Sicherheit erkennen konnte. Wie ich bereits oben erwälnte, gehen ans den beilen letyten Theilungen jeweils 4 Enkelzellen (Fig. 25) hervor, von denen jede 6 Chromosomen nnd zwar stets eins ans jeder Gruppe erhält. In Figur 26 habe ich eine umeife Samenzelle abgebildet und fällt auf den ersten Blick eine grosse Achnlichkeit mit cinem den beiden letzten Theilungren vorausgehenden Stadium (Fig. 14 und 15) auf; wie dort 6 Gruppen von je 4 Chromosomen vorlagen, so sind jetzt in derselben Anordnung 6 einzelne Chromosomen vorhanden, welche anch wieder Steruchenform besitzen und durch Lininfiden verbunden sind. Neben dem Kern befindet sich im Zellplasma ein ovaler Körper, der je nach der Conservirungsmethode einen verschiedenen Hahitus zeigt nnd dem entsprechend bald homogen bald knänelförmig zu sein scheint. Da ich uiber die Entstehung dieses Körpers keine weiteren Angaben machen kann, will ich denselben zunächst als Nebenkern bezeichnen (S. 122; man vergleiche die Erörterung bei Henking $\mathrm{Nr}$. 5 pag. 731 u. 725-726). In dem nächsten Stadium (Fig. 27) seben wir ein Spernaticl, welches aus einem rundlichen Kopf und langen Schwanz besteht. An dem Kopf beunerken wir einen kleinen Lufsatz, der offenbar aus dem Nebenkern hervorgegangen ist, während ler Kopf dem Zellker'u 
Zur Kenntniss der Spermatogenese von Gryllotalpa vulgaris Latr. 115

entspricht und noch deutlich die 6 Chromosomen erkennen lässt; der Schwanz ist, wie die Färbung meiner Präparate beweist, ans dem Zellplasma entstanden und hat folglich die gesammte Zelle an dem Aufbau dieses Spermatiden theilgenommen. Der reife Samenfaden (Fig. 28) zeigt einen spindelförmigen länglichen Kopf und langen Schwanz.

\section{Ueber amitotische Theilungen im Hoden vou Gryllotalpa.}

Für eine Entscheidung der Frage, welche Bedeutung der amitotischen Kerntheilung im Hoden zukommt, ist Cryllotalpa schon deshall) ungecignet, da die Nännehen nach einmaliger Spermaproduction za Grunde gehen and dic wichtige Specialfrage von der Neubildung von Samenzellen hierdurch von selbst in Wegfall kommt. Ieh eriunere aher daran, dass (wie sehon oben erwähnt wurde) während der Reife- und Unwandlungsperiode am blinden Eule jedes Follikels einige ruhende Zellen mit Regelmässigkeit zu finden sind, die offenbar einen Regenerationsherd hilden (palg. 110). Wenn num auch bei Gryllotalpa cine Samennenbildnng nieht erfolgt, so gibt uns las Vorhantensein lieser Zellen doch cinen Fingereig daffïr, an weleher Stelle wir bei andern Insecten, die mehremale Sperma prodnciren, den Regenerationsherd zu suchen haben. Bilder amitotischer Kerntheilungen sind übrigens bei Gryllotalpa wie bei den übrigen Insecten mit grosser Regelmässigkeit anzutreffen, und zumal während der Reife- und Umwandlungsperiode recht typisch und häufig wahrnehmbar. Einige solcher Kerne habe ich in Figm 29 и. 30 abgebildet; es gelang mir mehrfach in unmittelbarer Nähe der Kerne 2 winzige Centrosomen zu erkemnen (Fig. 29) und ebenso constatirte ich in seltenen Fïllen bei eingeschnïrten Kernen (Fig. 30) eine dentliche Strahlung um die beiden Centrosomen, die offenbar als Attractionsspluäre bezeichnet werden muss. Eine Verwechslung dieser Zellkerne (die nur von einem unregelmässigen Plasmahofe umgeben sind und keine Zellmembran erkennen lassen) mit Kernen ron Sexualzellen ist bei Gryllotalpa schon dureh den eigenthümlichen Habitus mol die relative Grösse der ersteren Kerne so gut wic ansgeschlossen. Die in Rede stehenden Zellen haben mit der Samenbildung selhst absolut nichts zn schaffen mol entsprechen den 
Zellen, welche ich in einer früheren Publication (Nr. 12a) als Rand- oder Stiitzzellen bezeichnete. Ith erimere hier daran, dass ich in derselben Publication bereits die Frage von der Bedeutnng der amitotischen Kerntheilung in Hoden eingehend disentirt habe; in nächster Zeit gedenke ich noch eimmal anf Grum meiner vergleichenden Untersuchungen anf denselben Gegenstand zurïckzukommen und auch die amitotischen Kerntheilungen der ${ }_{n}$ Spermatogonien" der Amplibien ${ }^{1}$ ) zu besprechen, die scheinbar eine Ausnalume von der von mir frïher anfgestellten Regel bilden.

1) Nachdem sehon von La VaIette St. George (Nr. 14),

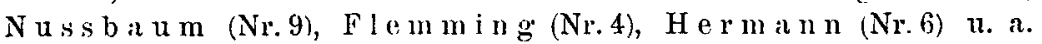
im Hoden von Amphibien und zumal bei Salamandra mac. neben rollkommen normalen und runden Spcrmatogonien anf eigenthümlich gelappte oder zerklüftete sogenannte polrmorphe Kerne in Zellan aufmerksam gemacht worden ist, die offenbar den Spermatogonien gleichwerthig sind (trauben- oler maulbeerfömige Kerntheilunge), hat in letzter Zeit Meves (Nr. 10) ansser diesen Bildern noch hantelförmige Kernelurehschnürungen und "Lochkerne" bei Spermatogonien des Salaminderhodens in einer vorliafigen Mitheifung besehrieben, ohne aber eine definitive Ansicht darüber auszusprechen, ob aus den Producten dieser anitotisclien Theilungen neue Sexualzellen hervorgehen. Ehe ieh dieser Frago gegenüber cine entscheidende Stcllung einnehmen kann, nuss dic definitive Arbeit von M e ves abgewartet werden. Ich möchte einstweilen nur soviel sagen, dass ich auf Grund meiner Untersuchungen bei Triton cristatus, alpestris und palmatus, sowie bei liana esculenta und Ranil fusca, die ich nebeneinander zu allen Jahreszeiten untersucht habe, behaupten muss, dass vou solchen durch anitotische Theilung entstandenen Kernen niemals oine Neubildung von Samenzellen ausgeht. In Uebereinstimmung mit Fle m in ing und $\mathrm{Meres}$ habe ich in der betreffenden Region des Hodens der Tritonen und Frösche, die offenbar ein Regenerationsfeld darstellt, viele Spermatogonien in mitotischer Theilung angetroffen, und nur von diesen aus geht die Neubildung der Follikel von Statten. Die durch amitotische Theilungen der Spermatogonien entstandenen Kernfragmente gehen langsam zu Grunde; manche von ihnen dürtten vielleicht bei der Follikelbildung noch als Rand-Stützzellen Verwendung finden. Die Annahme einer Unwandiung von solchen Kernliagmenten in Sexnalzellen ist nach meinen Befunden eine völlig unbewiesene und iiberflïssige Hypothese. Jch erinnere hier daran, dass von H. E. Zi egler (Nr. 16 and 17) und von mir (Nr.12a und 17) der Nachweis geliefert wurde, dass in den Organen, in welchen mitotische und amitotische Kemtheilungen nebeneinander vorkommen, die eigentliche Regeneration nur auf mitotischem Wege zu Stande kommt. 
Bestätigung der bei gryllotalpa gefundenen Resultate über die Reductionsfrage bei andern

Insecten, Crustaceen und Mollusken.

Ausser bei Gryllotalpa gelang mir das Zählen der Chromosomen bei eincm andern Insect, unserm grossen Wasserkïfer, Hydrophilus picens. Bei den Theilungen der Ursamenzellen fiund ich regelmaissig 16 Chromosomen. Vor der ersten Reductionstheilung ist die Zahl der Chromosomen auf 32 verdoppelt, die sich in der Nähe des Aequators in 2 parallelen Kränzen von je 16 anordnen. Jede Tochter\%elle erhält 16 ungetheilte Chromosomen und bei der zweiten Theilung, die wieder nit Ueberspringen des bläschenförmigen Ruhezustandes des Kerns zu Standle kommt, wird die Chromosomenzahl anf 8 heralgesetzt. Die Prophasen der ersten Theilung sind von denen bei Gryllotalpa beschriebenen einigermalssen verschieden; cine Ringbildung komnte ich nicht erkennen. die Bilder, die an lä̈utigsten \%ur Ansehanung kamen, erimnerten sehr an die von Hertwig bei Ascaris beschriebenen Ophiuren ähnlichen Figuren. Ein Zählen der Arme dieser Ophiuren war bei der Kleinheit des Objectes und der grossen /ahl der Arme nicht möglich.

Bei Dytiseus maryinalis liess die geringe Grösse der Chromosomen ein sicheres Zählen nicht zu, immerhin konnte ich vor der ersten Reductionstheilmug eine Längsspaltung des Chromatinfadens im Knäuclstadlium und eine Verdoppelung der Chromosomenzahl schätzungsweise feststellen. Die Samenbildung bei Dytiscus hat mehr Lehnlichkeit mit Gryllotalpa als mit Hydrophilus.

Unter den Crustaceen sah ich die Längsspaltung des Farlens und Verdoppelmug der Chromosomen bei der Samenbildung von Astacus fluviatilis, Branchipus stagnalis und mehreren Copepoden, ж. B. Heterocope saliens, Canthoeamptus (Spec.?), Encheta Prestandreae, Calanus gracilis. Bei den gleichen Copepoden constatirte ich, wic oben (Seite 11t) erwähnt wurde, eine Verdoppelung der Chromosomenzahl anch vor der ersten Theilung in der Ovogenese. Ich erinnere hier daran, dass bercits im vorigen Jahre V. Häcker in den Berichten der naturforschenden Gesellschaft in Freiburg (Juli 1891) in einer vorläutigen Mittheilung: für Cyclops und Canthocamptus in der Ovogrenese beide Theilungen als Reductionsprocesse dargestellt und eine Verdoppelung der Anzahl der "Elemente ${ }^{\prime "}$ vor der ersten Theilung constatirt hat ${ }^{1}$.

1) Während des Druckes diesser Sehrift urschien die definitive 
Das Studium der Zwitterdrüse einiger Mollusken (Pulmonaten) ergah folgende Zahlenverhältnisse. In der Samenbildung von Helix pomatia constatirte ich für die Theilnngen der Ursamenzellen die Chromosomenzahl 24, welche bereits von Platner (Nr. 11), als für Helix pomatia typisch bezeichnet wurde. Vor Ier ersten Rednctionstheilung war die Zahl auf 48 verdoppelt und diese 48 Chromosomen waren in Gruppen von je 4 mit einander durch Linin verbunden und zeigten so genau die Bilder, die ich für Gryllotalpa beschrieben und in Fig. $14 \mathrm{u} .15$ dargestellt labe, nur waren bei Helix pomatia stets 12 Gruppen von je 4 Chromosomen zu zählen. Selbstverständlich sind diese Verhialtnisse bei Helix pomatia wegen der doppelten Zahl der Chromosomen und der geringen Grösse derselben ungleich schwieriger zn erkennen als bei Gryllotalpa. Durch die erste Reductionstheilung wird dann bei Helix pomatia die Zahl der Chromosomen aut 24 und bei der zweiten Reduetionstheilung auf 12 herabgesetzt.

Wie Platner (Nr.11) für Limax agrestis die Chromosomenzalıl 16 feststellen komte, fand ieh dieselbe Zahl 16 anch bei den Theilungen der Ursamenzellen von Limax cineren-niger. Vor ter ersten Reductionstheilung erkannte ich 8 Gruppen von je 4 Chromosomen, also 32 Cliromosomen; nach der ersten Reductionstheilung zaihlte ich 16, nach der zweiten Rednetionstheilung 8 Chromosomen. Jetle der vier Samenenkelzellen erhält auf diese Weise trotz der zwcimaligen Reduction in Folge des Verdoppelungsprocesses bei Helix pomatia 12, bei Limax cinereoniger 8 Chromosomen, also die Hälfte der typischen Zahl 24 respective 16. Die Aehnlichkeit der Vorgänge vor den beiden Reductionstheilungen bei Gryllotalpa und den Pulmonaten und zumal die Gruppenbildung von je vier Chromosomen, ist von grosser Wichtigkeit and dürfte wesentlich dazu beitragen, die weiter unten noch näher za besprechenden scheinbar abweichenden Verhältnisse bei Pyrrhocoris apterus zu erklären.

Ich behalte mir vor einzelne besonders interessante Momente aus dem hier beiläufig erwähnten Beobachtungsmaterial gelegentlich ausführlicher zu beschreiben.

Arbeit von V. Hii cker" "Die Eihildung bei Cyclops und Canthocamptus" Zool. Jahrb. V. Bd. Auf den Inhalt dieser Arbeit kann ich hier leider nicht mehr eingehen. 
Zur Kenntniss der Spermatogenese von Gryllotalpa vulgaris Latr. 119

\section{B. Besprechung der Literatur.}

Aut die Arbeiten der Autoren, welche vor den grundlegenden Untersuchungen Hertwig's (Nr.7) Angaben ïber „Reductionstheilungen" in der Samenbildung (und zum Theil anch in der Eibildung desselben Objectes) enthalten, will ich hier nicht näher eingebn, da die wesentlichsten Gesichtspunkte sehon von 0 . Hertwig (Nr. 7) pag. 71-73, Heuking (Nr. 5) pag. 722-726 und Weismann (Nr.15) pag. õ6 ausführlich discutirt wurden. Ich beschränke mich daher aut einige kurze Angaben.

Die Annahme von van Beneden und Julin (Nr. 1), dass bei Ascaris meg. die corps résiduels (Zwischenkörperehen $\mathrm{H}$ e $\mathrm{r}$ twi g's) im Hoden den Richtungskörperehen entsprechen sollten, ist schon desshalb nicht haltbar; da es Hertwig gelang, anch in der Eiröhre desselben Thieres diese Gebilde nachzuweisen.

In wieweit man in den Untersuchungen Flemming's (Nr. 4) über die Samenbildung von Salamandra eine Reduction des Chronatins erkemnen kimn, ist von Hertwig (Nr. 7) pag. 71 n. 7 e mit gewohnten Scharfsinn ausgeführt. Ich möchte hicr aber nicht zu betonen unterlassen, dass es von grösster Wichtigkeit wäre, wenn noch einmal vom Gesichtspunkte der Reductionsfirage aus das Vorkommen rer heterotypen Theilung (Flemming gei Amphibien sturlirt und mit ähnlichen Vorgängen, wie sie z. B. Carnoy (Nr. 3) bei Arthropoden abgebildet hat, verglichen wïrde.

Dass Platner (Nr. 11) im Wesentlichen die Vorgänge in der Rerluction der Samenbildung bei Lepidopteren und Pulmonaten richtig erkannt hat, geht schon aus folgenden Sätzen hervor: „Die Spermatocyten entsprechen den Eiern. Die zwei Theilungen, welche sie noch eingehen, denen der beiden Richtungsspindeln. In beiden Fällen findet eine Reduction der chromatischen Substanz auf ein Viertel der ursprünglichen Quantität statt, indem die zweite Theilung olme eingeschaltetes Ruhestadium sofort an die vorhergehende sich anschliesst." _ „Bei der letzten Theilung der Spermatocyten findet eine Reduction der Chromosomen auf die Hälfte ihrer Zahl statt. Diese wird darlurch bewirkt, dass das Ruhestadium nach der vorhergehenden Theilung übersprungen wird. Genau der gleiche Process findet sich anch bei der Theilung der zweiten Richtungsspindel."

Ein Eingeben auf die Untersuchungen Carnoy's (Nr. 3), in 
dessen Abbildungen hin und wieder Reductionsvorgänge unverkennbar sind, wilrde hier zu weit führen.

Die wichtigsten Arbeiten iber die Reductionsfiage in der Simenhildung sind die Untersuchungen Hertwig's (Nr. 7) „Ueber die Ei- und Samenbildung der Nematoden", die von Henking (Nr. 5) „Ueber Spermatogenese und deren Beziehung zur Entwickelung bei Pyrrhocoris apterts", We is m in n's "Amplimixis" (Nr. 15), sowie Ishikaw a's Angaben „Ueber die Orogenese und spermatogenese von Diilptomus" (Nr. 8).

Die wichtigsten Sätze dieser Antoren werde ich zur Vermeidlung jeglichen Missverstïndnisses wörtlich citiren.

Hertwig lat die Resultate seiner Untersuchungen folgendermalassen formulirt:

1). Die Samenmutterzclle entspricht der Eimutterzelle oder dem nureifen Ei.

2) Während des länger dauernten Ruheznstandes des ansehnlichen bläsehentörmigen Kerns der beiden Geschlechtsproducte wirl die Kenusulstanz gleich fïl zwei Zelltheilungen, die sich mumittelbar aufeinander folgen, in eigenartiger Weise vorlhereitet.

3) Die im Keimblaisehen und in dem Simenmutterkern vorbereitete Menge wirksamer Kernsubstanz ist gleich gross, wie in jedem andern Kern vor der Theilung. Eine Reduction dureh Ausstossung oder Rüekbildung hat nicht stattgefunden.

4) Während der zwei unmittelbar anfeinander folgenden Theilungen findet cine Vermehrung der Kernsubstanz nicht statt, da das bläschenförmige Ruhestadium des Kerns ansfällt, und da die im Keimbläsehen und simennutterkern vorbereiteten chronatischen Elemente während der zavei Theilprocesse weder an Masse zunchmen, noch sich der Lïnge nich spalten. Die aus dem zwciten Theilungsact hervorgehenden Endproducte enthalten daher in Folge der zweimal eingetretenen Halbirung: nur die Hälfte der Kernmasse, welche cin gewöhnlicher Kern nach der einfachen Theilung besitzt.

5) Die Anzahl der im Simenmutterkern und Keimbläschen verbreiteten chromatischen Elemente ist bei Ascaris ebenso gross, wie bei einem gewöhnlichen Kerne in der Mitte des Theilungsprocesses, also die doppelte, wie sie ein Kern in der Vorphase der Theilung zeigt. Der morphologische Werth dieser Elemente scheint aber ein anderer $z u$ sein in Folge einer vom normalen 
Zur Kenntniss der Spermatogenese von Gryllotalpa vulgaris Latr. 121

Verlauf abweichenden Entstehung. Wührend normaler Weise acht Tochterchronosomen dureh einfache Längsspaltung von vier Fäilen entstehen, scheinen sie hicr durch doppelte Längsspaltung von nur zwei Fäden gebildet worden zu sein. Diese zwei Fäden enthalten aber dieselbe Substanzmenge, wie vier durch Quertheilung am Anfange der Karyokinese gebildete Fäden.

6) Da die Eimutterzelle und die Simenmutterzelle dieselhen Kerntheilungsprocesse nit allen ihren von der Norm abweichenden Eigenthümlichkeiten in genau der gleichen Wcise durchnuachen, miissen die Theilproducte auch denselben moiphologisehen Werth besitzen.

a) Den beiden Samentochterzellen entsprechen Ei und erster Richtungskörper.

b) Den vier Samenenkelzellen (Samenkörpern) sind das reife Ei, der zweite Richtungskörper und die aus Theilung des ersten Richtungskörpers entstehenden wvei Kügelehen zu vergleiehen.

c) Die Richtungskörper haben dlaher den morphologischen Werth rudimentiirer Eizellen."

Beiläufig möchte ich hier crwähnen, dasss Carl Camillo Schneider (Nr. 13) tür Ascaris megalocephala anf Grund eigener Untersuchumgen eine wesentlich andere Anffassung üher den Reductionsvorging vertritt.

„Die zwei rasch anfeinander folgenden Theilungen rer Eiund spermamutterzellen bewirken die Rerluction des Chromatins auf ein Viertel der ursprünglichen Menge. Die zwei Elemente der Keimzone (Asc. meg. univalens) vereinigen sich in der Wachsthunszone zu einem einheitlichen Chromatophor (die Abweichnng der Form desselben von der gewohnten deutet schon auf eine verschiedene Entstehungsweise hin), dieser wird geviertelt und das im Ei und Spermatozoon verbleibende Viertel im Stadium des Vorkernes verdoppelt, so dass aus diesem in die Furchungsspindel von beiden Seiten je ein normaler Chromatophor eingeht."

Die Vergleichung der Entwicklung von Ei und Samen bei Pyrrhocoris ergiebt nach Henking (Nr. 5) das Folgende:

1) Den Ursamenzellen entsprechen die Ureier. Beide Zellformen enthalten die für die Körperzellen characteristische Zahl von 24 Chromosomen.

2) Den unreifen Eiern entsprechen die Samenmutterzellen (Spermatocyten I. Ordn.). Beide wachsen erheblich heran, in 
beiden kommt es zur Aushildung eines verhältnissmässig grossen bläischenförmigen Kernes, in beiden werden Dotterkügelchen erzeug't.

3) Die Abschnürung des ersten Richtungskörperchens entspricht der ersten Theilung des Spermatocyten. In beiden Fällen kommt es zu einer Weismann'schen Rednetionstheilung, indem sich die Chromosomen , 'xweireihig $^{*}$ aufstellen und zu je 12 Elementen in die nenen Zellen übergehen. Die typische Zahl 24 wird also hier durch einfache Trennung der chromatischen Elemente auf 12 reducirt.

t) Die Aushildung des zweiten Richtungskörpers entspricht der zweiten Theilung der Spcrnatocyten. Die 12 ehromatischen Elemente werden unter Beibehaltung der Zahl durch Aequationstheilung direct halbirt, olne dass sich das Stadium eines ruhenden Kernes dazwischen einstellte. Die sofortige Theilung der Spermatocyten II. Ordn. wurde möglich, weil dic vorhergehende erste Theilung nicht als normal anzusehn ist und weil die letztere wahrscheinlich bewirkte, dass sich gleich dic auch für eine zweite Theilung nöthige (also doppelte) Zahl achromatischer Fäden an die Chromosomen anheftete.

Fiur das spermatosom ist noch Folgendes bemerkenswerth.

1) Aus den peripherischen Verbindungsfasern und unter Betheiligung vou Spindelfasern entsteht der Nehenkern. Die Dottermasse wird gewissermaassen als Fïllmaterial bei Bildung desselben benutzt.

2) Das centrale Bündel der Verbindungsfasern lässt aus sich das Mitosoma hervorgehn.

3) Der paarig gewordene Nebenkern haftet sich hinten an den zum Kopfe werdenden Kern an und durchzieht den Schwanzfaden.

4) Das dem Kern zugewandte Stück des Mitosoma wird cbromatisch und wandert als Spitzenkopf an das vordere Ende des Samenfadens.

5) In Nebenkern und Mitosoma sind wahrscheinlich kleine Mengen von Chromatinsubstanz übergegangen.

6) Es sind zwei verschiedenwerthige Arten von normalen Samenfäden vorhanden. Die einen enthalten nur 11 chromatische Elemente, dic anderen ausser 11 chromatischen Elementen auch 
noch ein einzelnes zuletzt ungetheilt gebliebenes Chromatinelement, welches wahrscheinlich als Nucleolus anzusehn ist."

Während also nach Hertwig bei der Samen- und Eibildung von Ascaris meg. bei der aveiten der beiden letztern unmittelbar anfeinander folgenden Theilungen eine Herabsetzung der Anzahl der chromatischen Elemente auf die Hälfte der ursprünglichen Zahl stattfindet, wodurch verhindert wird, ndass durch die im Befruchtungsact erfolgende Verschmelzung zweier Kerne eine Summirung der chromatischen Substanz und der chromatischen Elemente auf das Doppelte des für die betreffende Thierart geltenden Normalmatssses herbeigefïhrt wird", findet nach Henking in der Ei- und Samenbildung von Pyrrhocoris apterus die gewünschte Reduction schon bei der ersten der in Rerle stehenden Theilungen statt und wirl die zweite Theilung als eine gewöhnliche Aeqnationstheilung bezeichnet. Henking versucht ferner die von Hertwi gr gewonnenen Resultate mit seinen Befunden in Einklang zu bringen, indem er überhaupt die Verdoppelung der Zahl der Chromosomen bei Ascaris vor der ersten Theilung anzweifelt, was allerdings nicht angeht (vgl. Weismann's Amplinixis pag. 35). Bei diesem wenig glückliehen Erklärnngsversuche betont aber Henking mit Reeht, "dass bei der Annahme von acht selbständigen Elementen bei Ascaris es streng genommen auch sehon bei der ersten Halbirung zu einer Redluctionstheilung kommt; denn es gehen vier Chromosonen in die Tochterzelle iiber, ohne auf der Höhe des Aequators eine Aequationstheilung erfahren zu hahen."

In einer vorläufigen Mittheilung (Nr. 12b) habe ich bereits im September vorigen Jahres darauf hingewiesen, dass man ausser bei Ascaris meg. nach meinen eigenen Befunden auch bei Gryllotalpa vulgaris von einer zweimaligen Reduction sprechen könne, da die 12 Chromosomen der Ursamenzellen dieses Insectes vor der ersten der in Rede stehenden Theilungen zu 24 verdoppelt, durch die erste Theilung wieder anf 12 gebracht und durch die zweite Theilung auf 6 herabgesetzt werden.

Kurze Zeit nach dieser Mittheilung ersehien Weismann's wichtiges Buch "Amphimixis", in welchem unter anderem der Nachweis geliefert wird, dass trotz des scheinbaren Widerspruches in den Resultaten von Hertwig und Henking eine Vereinbarung doch möglich ist, wenn nämlich die empirischen Befunde beider Autoren eine andere Deutung erfahren. Naeh Weismann sind 
sowohl bei Ascaris meg. als bei Pyrrhocoris apt. beide letatern Theilumgen sowohl in der Ei- als samenbildung als Reclnetionstheilungen aufzufassen.

Beinahe gleichzeitig mit dem eben genannten Werke publicirte C. Ishikiwa (Nr. 8) seine Arbeit über Spermatogenese, Ovogenese und Befruclitung bei Diaptomus. Nach Ishikawa findet in der Ei- und Samenbildung dieses Copepoden die srewiinschte Reduction bei der letzten Theilung statt. Die wesentlichsten Resultate seiner Untersuchungen hat genannter Autor in folgenden Sätzen zusammengestellt.

1) The primary sperm cells correspond exactly with the primary ego-cells. Both contain eight chromatic elements.

2) In both ceils the eight chromosomes become constricted transversely giving rise to eight dumb-bell shaped bodies. These arrange themselves in an equatorial zone and begimn to divide in such a mamer that balf of each chromosome gocs to one cell and the other half to the other. This kind of ecll-division takes place two or three times and the resulting cells form the mother cells of eggs or spermatozoa, as the case may be.

3) These grow considerably; after which.

4) They hegin to divide as hefore; each chromosome dividing transversely. This stage corresponds in the egir to the formation of the first polar body, which takes place exactly in the same manner as that of the first division of the sperm-mother cell. In both cases the original eight ehromosomes become divirled into two, giving rise to the daughter cells also containing eight chromosomes (Weismann's $n$ Aequationstheilung ${ }^{*}$ ).

כ) This is immediately followed by another division, without an intervening resting stige of the nuclei, and by reduction in the original number of chromosomes (Weismann's „Reductionstheilung: $\left.{ }^{4}\right)$. The eight chromosomes which at first are arranged in a single row become arranged in double rows of four each, and the cell begins to divide in such a manner that four chromosomes go to one cell and the remaining four to the other.

By divisions described under Nr. 4 and 5 a sperm-mother cell as well as an ego-mother cell increases to four cells, which in case of the former give rise to four spermatozon, while in that of the latter a single egg. cell with two polar bodies, results (or three when the first polar body divides). 
Zur Kenntniss der Spermatogenese von Gryllotalpa vulgaris Latr. 125

6) During the formation of the second polar body the spermatic cell enters into the egor-cell. The nucleus of the sperm cell is, as a general thing, at first rather small and colours deeply and homogeneously, but soon the differentiation sets in and the four chromosomes become ilistinctly visible. The nucleus of the egg-cell remaining after the formationt of the second polar body - the female pronucleus of Ed. van Beneden -- shorvs at first distinctly four elements. These soon grow longer, show many convolutions, and pass into a "skein" stage.

7) The two nuclei gradually approach one another until they come in close contact, but they do not unite into a single piece before the equatorial plate is formed. The number of chromatic elements in each of the copnlating nuclei is now found to be eight, exactly double the number present in the nuternal nucleus after the expnlsion of the sceond polar body, and in the ripe spermatozoon.

This number goes unchanged to the formation of the first segmentation spindle, which gives rise to two first segmentation spheres, each of which contains eight single chromosomes."

Aus den theoretischen Betrachtungen Ishikawas will ich noch folgenclen Passus citiren:

${ }_{n}$ Henking tries also to make his observations coineile will those of Hertwig upon Ascaris by giving different interpretations to the resnlts obtained by the latter investigator. Whatewer may be the interpretation in the case of Ascaris, my own case, given above, can not to $\mathrm{my}$ mind be made to coincide with his observation on Pyrrhocoris. I will not, however, assert the "Reductionstheilung." in the formation of the second polar body and in the last cell division in the spematogenesis to be the miversal rule until a sufficient number of observations be obtained in other groups of animals and perhaps of plants too. Theoretical cousiderations concerning the phenomena of fertilization lead us in all probability to the ${ }_{n}$ Rednctionstheilung ${ }^{*}$ as occuring in the second polar body and in the last division of spermatic cells."

Vergleichen wir jetzt eimmal der Reihe nach die Befunde der eben genannten Autoren mit meinen Resultaten, so werden wir sehn, dass einer einheitlichen Anffassung der Reductionsvorgainge nichts im Wege stelt, wenn man nur eine geringe denderuug in der Dentung dieser Befunde vornimmt. Yit den Hert- 
wig'schen Angaben stehen meine Resultate in vollem Einklang; wenn man nach dem Vorgang von $\mathrm{W}$ e is $m$ an $\mathrm{n}$ ( $\mathrm{Nr}$. 15) die 8 Stäbchen von Ascaris meg. bivalens vor der ersten Theilung. als selbständige Stäbchen auffasst, dann sind anch beide Theilungen in der Ei- und Samenbildung von Ascaris als Reductionstheilungen zu bezeichnen, indem die 4 Stïbchen der Urei- und Ursamenzellen vor der ersten Theilung auf 8 verdoppelt, durch die erste Theilung auf 4 und durch die zweite Theilung anf 2 herabgesetzt werden.

Auch die Angaben Canillo Schneider's (Nr. 13) bei Ascaris meg. univalens stehen weder mit meinen Befunden, noch mit meinen Deutungen in einem so schroffen Widerspruch als es anf den ersten Blick erscheint. Nach Schneider treten die 2 Stäbchen der Urei- und Ursamenzelle vor der ersten R-Theilung als ein einheitlicher "Chromatoplior" auf, dieser wird dann durch die beiden Theilungen geviertelt. Ich erinmere zunächst daran, dass Carnoy, van Gehuchten und Hertwig jedes Stäbchen als cin chromatisches Element auffassen, während van Beneden, Julin, Boveri und Sehneider die Gruppe von 4 staibehen als ein einziges chromatisches Element be\%cichnen, welches aber nach Boveri (Nr. 3) schón in 4 Unterabtheilungen goesondert und viertheilig ist. Der Unterschied der Angaben liegt mehr in der Deutung als in der Beobachtung. Bei Gryllotalpa sind nun auch stets 4 Chromosomen zu einer Gruppe vereinigt, aber die Verbindung wird dureh Linin hergestellt und nicht dureh Chronatin.

Ob nun die Verbindung des viertheiligen Chromatophors von Ascaris meg. univalens anch durch Linin oder durch Chromatin vermittelt wird, ist der strittige Punkt; bei ersterer Annahme, die nach der Hertwigr'sehen Darstellung viel Wahrscheinlichkeit für sich hat, wïrden die 2 Stäbchen der Urei- und Ursamenzellen vor der ersten Theilung zu 4 verdoppelt sein und so der Annahme einer zweimaligen Reduction nichts im Wege stehn; aber selbst wenn bei Asearis die 4 Chromosomen dureh Chromatin zu einer Einheit verbunden sind, so könnte daraus keine principielle Differenz abgeleitet werden, da ja die Chromosomen von Gryllotalpa im Ringstadium anch zu je vieren aus einer Einheit hervorgehn. Wir schn, dass die Vorgünge bei Ascaris und Gryllotalpa sich sehr gut mit einander vergleichen lassen, nur liegen die Verhält- 
Zur Kenntniss der Spermatngenese von Gryllotalpa vulgaris Latr. 127

nisse bei Gryllotalpa viel klarer vor Augen, da über die Verdoppelung der Chromosomen vor der ersten Theilung, sowie über die Verbindung von je 4 Chromosomen zu einer Gruppe gar kein Zweifel autkommen kann.

Von besonderer Wichtigkeit ist ein Vergleich der Samenbildung von Pyrrhocoris mit der von Gryllotalpa, da sehr viele ubereinstimmende Momente angetroffen werden und so eine einheitliche Deutung der Befunde bei beiden Insecten erleichtert wirl. Wenn die von Henking für seine Befunde aufgestellte Deutung die richtige wäre, dann würde Pyrrhocoris eine eigenthiimliche schwer begreifliche Ausnahmestellung in Beang anf den Reductiousprocess eimnehmen; ich glanbe aber, dass die von Weismann in seiner Amphimixis gegebene Dentung der Henking'schen Befunde viel mehr dVahrscheinlichkeit beanspruchen darf. Nach Weismann sind die 24 Idanten (Chromosomen) von Pyrrhocoris vor der ersten Theilung, die also der Zahl nach den Ilanten der Ursamenzelleng gleich wären, in Wirklichkeit Doppelidanten (Doppelchromosomen). Jede Tochterzelle erhält bei dieser Auffissung 12 Doppelidanten und jede Enkelzelle 12 einfiche Idanten (conf. Weismann, Amphimixis S. 53-61). Vergleichen wir jetzt einmal die Abbildungen Henking's mit meinen, so werden sofort bei den Vorgängen vor der ersten R-Theilung einige Aehnlichkeiten in die Augen fallen. Bei beiden Insecten kommt es zu einer Ringbildung, aus weleher die definitiven Chromosomen sich heraus bilden, während aber bei Gryllotalpa die 6 Ringe glcichzeitig auftreten und sich ans ihnen kure Zeit später 24 Chromosomen herausdifferenziren, gehen diese Vorgänge bei Pyrrhocoris nebencinander einher, so dass man die 12 Ringe nie gleichzeitig erkennen kann, sondern stets einige Ringe und einige fertige Chromosomen sieht. Durch letzteren Unstand wird ein genatuerer Einblick in diese Vorgänge bei Pyrrhocoris wesentlich erschwert. Bei Gryllotalpa gehen, wie ich oben gezeigt habe, in die Ringbildung jeweils 4 Chromatinfäden ein, von denen jeder ein em Chromosom entspricht, und aus jedem Ring' differenziren sich nachher wieder 4 Chromosomen beraus. Nach Henking (Nr. 5) soll aber jeder Riug nur 2 Chromosomen entsprechen. Von besonderer Wichtigkeit für die Beurtheilung dieser Frage ist die Fig. 20 bei Henking l. c., da in dieser Abbildung deutlich Ringe mit 4 Verdickungen zu selm sind. Vergleichen wir diese Fig. 20 
mit meinen Figuren 14 a. 15, so liegt der Gedanke nahe, ob nicht auch bei Pyrrhocoris jeder Ring 4 Chromosomen entspricht. Ich erimnere daran, dass auch bei Gryllotalpa bei den beilen letzten Theilungen stets 2 Chromosomen einander genähert sind und ein Paar bilden, bei Pyrrhocoris könnte eine noch weiter gehende Vereinigung eines Chromosomen-Pares bis zu einer scheinbareu Verschmelzung stattgefunden haben. Bei dieser Auffassung ist anch die zweite 'Theilung bei Pyrrhocoris keine tequationstheilung im Sinne Weismann's (Nr. 15), vielmehr dürfen beide Theilungen als Reductionstheilungen bezeichnet werden, indem bei beiden Theilungen Doppelchromosomen oder Parlinge von eipander getrennt werlen. Weismann möchte annehmen, dass bei der aweiten Theilung der Mutterzellen von Pyrrhocoris "lie Ide zweireilig nebeneinander stehen und dass der Idant eigentlich ein Doppelidant ist." 0 b nun die Ringbildung wie bei Gryllotalpa der Gruppenbildung von je 4 Cluromosomen voransgeht, oder ob in umgekehrter Reihenfolge aus der Vierergruppe der Ring gebildet wirl, wie Weismann es schematisch für Pyrrhocoris dargestellt hat, ist im Wesentlichen völlig grleichgoiltig und scheint nach meinen vergleichenden Beobachtungen bei verschiedenen 'Thieren verschicden zu sein. Nach den Abbildungen Carnoy's (Nr.3) ist das Chromatin in der Aequatorialebene vieler Spindelfiguren, die offenbar der vorletzten Theilung zuzurechen sind, in deutlichen Ringen angeordnet, die dann dureh die beiden anfeinander folgenden Theilungen in 4 gleich grosse Abschnitte, die 4 Chromosomen entsprecben, getheilt werden.

Die Befunde Ishikawa's bei der Ei- und Samenbildung: von Diaptomus scbliessen sich direct den Hertwig'schen Resultaten an und soll auch bei diesem Objecte bei der zweiten Theilung die Reduction des Chromatins stattfinden; auf Grund eigener Untersuchungen iiber die Ei- und Samenlsildung der bereits oben erwälnten Copepoden des süssen Wassers, Canthocamptus und Heterocope, sowie vieler mariner Formen, z. B. Eucheta, Calanus u. a. glaube ich, dass die Befunde Ishikawa's auch cine andere Deutung zulassen. Ishikawa betont zunächst ansilrieklich, dass bei den Theilungen der Ursamenzellen und Ureizellen die Chromosomen quer getheilt werden. "The only difference from the ordinary karyokinesis consists in the mode of division of the chromosomes, which generally divide 
Zur Kenntniss der Spermatogenese von Gryllotalpa vulgaris Latr. 129

longitudinally and not transversely." Bei den von mir untersuchten Copepoden finclet bei den Theilungen der Urei- und Ursamenzellen im Kuäuelstadium eine Längsspaltung des Chromatinfadens statt, und ich bin daher geneigt die Theilungen der Chromosomen als Lüngstheilungen aufzufassen. Ferner bezeichnet Ishikawa die erste Theilung nach der Ruheperiode in der Eiund Samenbildung seines Untersuchungsobjectes als eine Aequationstheilung, da die 8 Chromosomen, welche bereits bei den Theilmugen der Urei- und Ursamenzellen vorhanden waren, bei der ersten Theilung auf der Höhe des Aequnators y $n$ e r getheilt und somit den 'Tochterzellen wieder 8 Chromosomen moreführt werden. Bei den ron mir untersuchten Copepoden findet aber vor der ersten Theilung in der Ei- und Samenbildung eine muverkembare Längspaltung, des Fartens und Verdoppelung der Chromosomenzahl statt, so dass es mir wahrscheinlich erscheinen nutss, dass anch bei Diaptomus keine eigentliche Durchsehnïrmug der $\&$ (hanteltörmigen) Chromosomen auf' der Höhe des Aeryators vor' der ersten Theilung stattindet, lass vielmehr wie bei allen von mir beobachteten Fällen die verdoppelten, also 16 Chromosomen sich gleich "xweireihig" (das heisst in zwei parallelen Krinzen von je \& Chromosomen) antstellen uml anf diese Weise jede Tochterzelle bei der ersten Theilung 8 und bei der zweiten Theilung 4 Chromosomen crhält. Die Abbildungen Ishikawa's l. e. lissen eine solche Iuffassung von zwei Reductionstheilunoren sehr wohl zu, ich verweise zumal auf lig. 25,26 n. 27.

Nach der vorstehenden Besprechung, darf es wolıl als Regel angesehen werden, dass sowohl in der Ovog'enese als in der Spermatogenese stets eine mehr oder weniger deutlich erkembare Verdoppelung der typischen Chromosomenzahl vor der vorletzten Theilung stattfindet, und dass dureh die erste 'Theilung dic ulsprüngliche Zabl der Chromosomen wieder erreicht und bei der "sweiten Theilung auf die Hülfte herabgesetzt wird.

Da nun aber die Natur die Herabsetzung der Chromosomeuzahl auf die Hültte auf viel einfacherem Wege erreichen kann, muss der complicirte Vorgang der Verdoppelung und zwcimaligen Theilung eine besondere Bedentung haben. Nach Weismanu liegt die Bedeutung dieser Verdoppelung ,in dem Bestreben, eine möglichst vielgestaltige Mischtmg der rom Vater und von der Mutter herstammenden Vererbungs-Einheiten herbeizutühren." Der 
Sinn der Längsspaltung und Verdoppelung der Idanten vor der Reductionstheilung bestände darin, „eine fast unendliche Zahl von versehiedenen Keimplasma-Mischungen zu emöglichen, um dadurch die individuellen Unterschiede in so vielen verschiedenen Combinationen der Naturzïchtung zur Verfügung zu stellen, als Individuen entstehen". - "Die beiden Theilungen der KeimMutterzellen bedeuten eine Periode der Reduction und des Umbaues des Idioplasmas. Handelte es sich blos um eine Reduction, d.h. Verminderung der Id-Ziffer auf die Hälfte, so würde eine einzige Theilung genügt haben; die zweite wurde dadurch nöthig, dass zugleich eine möglichst grosse Manniglaltigkeit des Keimplasmas erreicht werden sollte." Für das Zustandekonmen von solchen Combinationen sind die Ring- oder Kranzbildungen von grosser Wichtigkeit, rorausgesetzt, -dass die aus der Kranzbildung: hervorgehenden Doppelidanten von den Doppelidanten, welehe in dic Kranzbildnng eintreten, in Bezug anf die Anordnung und Vertheilung der Ide verschieden sind. Es würde dann die Kranzbillung des Idlioplasmas bei der Reductionstheilung der Keimzellen eine Neugruppirmg der Ide zum Zwecke haben (conf. Amphimixis pag. $59-61$ u. Fig. VII).

Hinsichtlich der grenaneren Ausfïhrung der Weismann'schen Ansichten will ich anf' die Originalarbeit verweisen, da ich hier nicht in eine Besprechung der theoretischen Fragen eintreten möchte, sondern nur die Abklärung und Feststellung des thatsächlichen Verlaufes der Vorgänge beabsichtigte.

$M \ddot{a} r^{r}, 1892$.

\section{Literatur.}

1. van Beneden u. Julin, La spermatngènèse chez l'ascaride mégalocéphale. Bulletins de l'académie royale de Belgique. 1884.

2. B overi, Zellenstudien. Jenaische Zeitschrift für Naturwissenschaft. $1887-1890$.

3. Carnoy, Cytodiérése des Arthropodes. La Cellule T. 1. 1885.

4 Fle m m in g., Neue Beitritge zur Kenntniss der Zelle. Arehiv f: mikr. Anat. Bd. 29, 1887.

5. Henking gänge in den Eiern der Insekten. II. Ueber Spermatogenese und deren Beziehung zur Entwicklung bei Pyrrhocoris apterus L. Zeitschr. t', wiss. Zool. LI. 4. 1891. 
Zur Keuntniss der Spermatogenese von Gryllotalpa vulgaris Latr. 131

6. Hermann, Beitrag zur Lehre von der Entstehung der karyokinetisehen Spindel. Arch. f. mikr. Anat. Bd. XXXVII.

7. O. Hertwig, Vergleich der Ei- und Samenbildung bei Nematoden. Arch. f. mikr. Anat. Bd. 36. 1890.

๖. C. Ishikawa, Studies of Reproductive Elements. I. Spermatogenesis, Ovogenesis and Fertilization in Diaptomus Sp. Reprinted from the Journal of the College of Science, Imperial University, Japan. Vol. V, Pt. I. 1891.

9. UI. $\mathrm{Nuss}$ b a u m, a) Zur Differenzirung des Geschlechts im Thierreich. Arch. f. mikr. Anat. Bd. 18.

b) Ueber die Veriinderungen der Geschlechtsproducte bis zur Eifurchung, ein Beitrag zur Lehre von der Vererbung. Arch. für mikr. Anat. Bd. 23.

10. Meves, Ueber amitotische Kerntheilung in den Spermatogonien des Salamanders etc. Anat. Anzeiger Nr. 22, 1891.

11. P a t n e r, a) Die Karyokinese bei den Lepidopteren als Grundlage für eine Theorie der Zelltheilung. Intern. Monatsschr. f. Anat. u. Histol. Bd. IIT. 1886.

b) Beitriige zur Kenntniss der Zelle und ihrer Theilungserscheinungen. Arch. f. mikr. Anat. Bd. 33, Heft 1 u. 2. 1889.

12. vom $\mathrm{R}$ ath, a) Ueber die Bedeutung der amitotischen KerntheiIrmg im Hoden. Zool. Anzeiger Nr.373-375. 1891.

b) Ueber die Reduction der chromatischen Elemente in der Samenbildung von Gryllotalpa. Berichte der naturf. Gesellschatt zu Freiburg i. B. Bd. VI, Heft 9. 1891.

13. Carl Camillo $\mathrm{Schneider,} \mathrm{Untersuchungen} \mathrm{iiber} \mathrm{die} \mathrm{Zelle,}$ Arbeiten aus dem zool. Institute der Univ. Wien. Tom. IX. 1891.

14. v. La Valet te $\mathrm{St}$. G e orge, a) Ueber die Genese der Samenkïrper. Arch. f. mikr. Anat. Bd. III. 1867.

b) Spermatologische Beiträge 1.-5. Mittheilung. Arch. f. mikr. Anat. 1885-1887.

c) Zelltheilung und Samenbildung bei Forficula anricularia, in: Festschrift zu v. Köllike er's 70. Geburtstage. 1887.

15. We i s m a n n, Amphimixis. Jena 1891.

16. Ziegler, Die biologische Bedentung der amitotischen Kerntheilung im Thierreich. Biol. Centralbl. Bd. XI. 1891.

17. Zi egleg $u$. vom $R$ ath, Die amitotische Kerntheilumg bei den Arthropoden. Biol. Centralbl. Ba.XI. 1891.

\section{Erklärung der Abbildungen auf Tafel V.}

Simmtliche Figuren beziehen sich auf Gryllotalpa vulgaris Latr. und sind mit Seibert's Apochrom. Homog. Immersion 1,5 mm, Apert. 1,30 , Oc. 8 gezeichnet. Vergrr. ca. 1334 . Einzelheiten wurden bei noch stiirkeren Vergrössemungen cingetrngen. 
Fig. 1. Ursamenzelle mit blaischenförmigem Kern (Ruhestadium).

Fig. 2. Ursamenzelle in Vorbereitung zur Theilung. Das chromatische Netzwerk ist wesentlich derber und deutlicher geworden.

Fig. 3. Zusanmenballen des Chromatins an einer Kernscite.

Fig. 4. Qnerdurchschnürung des chromatischen Doppelfadens in 12 Segmente a) nach einem Schnitte; b) nach einem Zupfipraiparate.

Fig. 5. Spindel in Seitenansicht.

Fig. 6. Die Aequatorialplatte der Spindel wird in etwas sehriger Richtung gesehen.

Fig. 7. Beginn der Tremung zweier Tochterzellen.

Fig. 8. Verschiedene Ansichten der Aequatorialplatten der Tochterzellen.

Fig. 9. Eine rosettenförmig angeordnete Gruppe vou Samemmuttorzellen in Ruhestadium, gegen Ende der Wachsthnmsperiode (Periode II).

Fig. 10. Samenmutterzelle in Vorbereitung zur Theilung.

Fig. 11. Knäuelstadium ohne erkemnbare Verdoppelung des chromatisehen Fadens.

Fig. 12. Knäuelstadium mit Längsspaltung des Fidens, aber ohne Quertheilungen.

Fig. 13. Der chromatische Doppelfaden ist durch Quertheilungen in 6 Segmente zergliedert; a) nach (dine'm S(chnitt; b) und c) nach Zupfpripariten; d) aus den if Segmenten sind dureh Vorlöthen der freien Enden of Ringe entstanden.

Fig. 14 n. 15. Atus den 6 Ringen haben sich 6 Gruppen von je 4 Chromosomen heratusdifferenzirt, in Fig. 14 etwas schematisirt nath einem $\mathrm{Zup}$ ipriiparat, in Fig. 15 nach cinem Schnitt naturgetren largestellt.

Fig. 16. Zusammenziehen der 6 Gruppen nach dem Kerncentrum, und Anordnung der 24 Chromosomen in 2 parallelen krinzen von je 12 Chromosomen.

Fig. 17 u. 18. Zwii Ansichten anf die Aequatorialplatte der ersten Theilungsspindel (der Reifungsperinde) vom Pol aus gesehen.

Fig. 19. Seitenansicht der Spindel der ersten Theilung.

Fig. 20 u. 21. Verlaut der ersten Theilung.

Fig. 22, 23 u. 24. Verlauf der zweiten Theilung.

Fig. 25. Die aus den beiden Theilungen einer Samenmutterzelle hervorgegangenen 4 Samenenkelzellen vor der Anaphase.

Fig. 26. Samenenkelzelle vor dem Beginn der Unwandlungsperiode.

Fig. 27. Unwandlung einer unreifen Samenzelle (Spermatid) zu einem Samenfaden (Spermatosom, Spermatozoon).

Fig. 28. Reifer Samenfaden.

Fig. 29. Kern einer Randzelle (Stützzelle) mit 2 Centrosomen.

Fig. 30. Eingeschnürter Kern einer Randzolle (Stützzelle) mit 2 Centrosomen und einer Attractionssphiire. 